\section{Determinação de atividade antimicrobiana de extratos de plantas de uso popular como antiflamatório}

\author{
N. Caetano ${ }^{1 *}$; A. Saraiva ${ }^{1}$; R. Pereira ${ }^{1}$; D. Carvalho'; M.C.B. \\ Pimentel$^{2}$; M.B.S. Maia ${ }^{3}$
}

${ }^{1}$ Departamento de Ciênicas Farmacêuticas, AV. Professor

Artur de Sá, s/n, Cidade Universitária, Universidade Federal de Pernambuco, 50670-420, Recife, PE, Brasil

2 Departamento de Bioquímica

${ }^{3}$ Departamento de Fisiologia e Farmacologia

nellyta26@.hotmail.com
(Alternanthera brasiliana) indicadas popularmente por seu uso como antiinflamatório ${ }^{5,12}$ foram estudados farmacologicamente verificando-se a ação para babaçu ${ }^{11}$ e cardo santo.

De outra parte as plantas citadas foram já estudadas no caso do mentrasto quanto sua toxicidade, nas condições otimas de produção de óleo essencial ${ }^{6}$, como fonte produtora de $\mathrm{Fe}^{10}$ e pela sua atividade antimicrobiana sobre bactérias Gram-negativas e bactérias Gram-positivas, entre as quais Streptococus pyogenes ${ }^{14}$.

O babaçu, pala sua vez foi estudado quanto sua atividade antitumoral ${ }^{13}$, e pela sua atividade antiulcerogénica ${ }^{8}$.

A terramicina (Alternanthera brasiliana) tem sido objeto de estudos sobre suas condições de cultivo, composição química e ação analgésica, assim como a determinação de condições de produção de seu pigmento betacianina ${ }^{3}$, quanto toxicidade e composição química4.

No presente trabalho propomos o estudo de uma possível atividade antimicrobiana frente a cepas padrões ATCC e isolados hospitalares de Staphylococcus aureus, visto que entre as infecções comunitárias e nosocomíais aquelas produzidas pelos Staphylococcus aureus tem lugar de destaque pela sua frequência, morbidade e mortalidade e principalmente pelas dificuldades de tratamento. Ainda tem sido reportado que infecções de lesões da pele com Staphylococcus aureus meticilina resistente (MRSA) constituem um sério problema no processo de cicatrização.

Assim serão determinadas a atividade antimicrobiana das plantas babaçu (Orbignya martiana), cardo santo (Argemone mexicana), mentrasto (Ageratum conyzoides), cavalinha (Equisetum yeamalis) e terramicina (Alternanthera brasiliana) frente as cepas de Staphylococcus aureus.

\section{Material e Métodos}

As cepas de Staphylococcus aureus usadas no teste são apresentadas na tabela 1 . No estudo são retidas duas cepas padrões (ATCC) de reconhecida resistência, utilizadas nos testes para conservantes e desinfetantes, cinco isolados hospitalares: três meticilina sensível e dois meticilina resistente.

As plantas com seus extratos são apresentados na tabela 2, todos os testes foram realizados com extratos aquosos obtidos a partir de liofilizados de extratos hidroalcóolicos (1:1) das referidas plantas.

No caso da Alternanthera brasiliana (terramicina) o extrato tinha uma consistência mais pastosa, que dificultou a pesada.

A metodologia empregada foi a técnica de discos por difusão em ágar e a técnica de poços por difusão em ágar, utilizando-se como antibiótico padrão: cloridrato de tetraciclina (solução mãe $1 \mathrm{mg} / \mathrm{ml}$ ) e como meio ágar Müeller Hinton semeado na superfície com os inóculos bacterianos. O uso de dois ou mais métodos para o estudo da atividade antimicrobiana permite obter melhores resultados ${ }^{9}$. As placas foram deixadas em repouso por 40 min à temperatura ambiente antes de incubar (tempo de predifusão). da medicina tradicional para seus cuidados primários de saúde, bem a partir, do uso de extratos de plantas ou de seus princípios $\operatorname{ativos}^{1,2,7}$.

As plantas em estudo: babaçu (Orbigiaya martiana), cardo santo (Argemone mexicana), mentrasto (Ageratum conyzoides), cavalinha (Equisetum yeamalis) e terramicina 
Tabela 1. Origem das cepas de Staphylococcus aureus testadas*

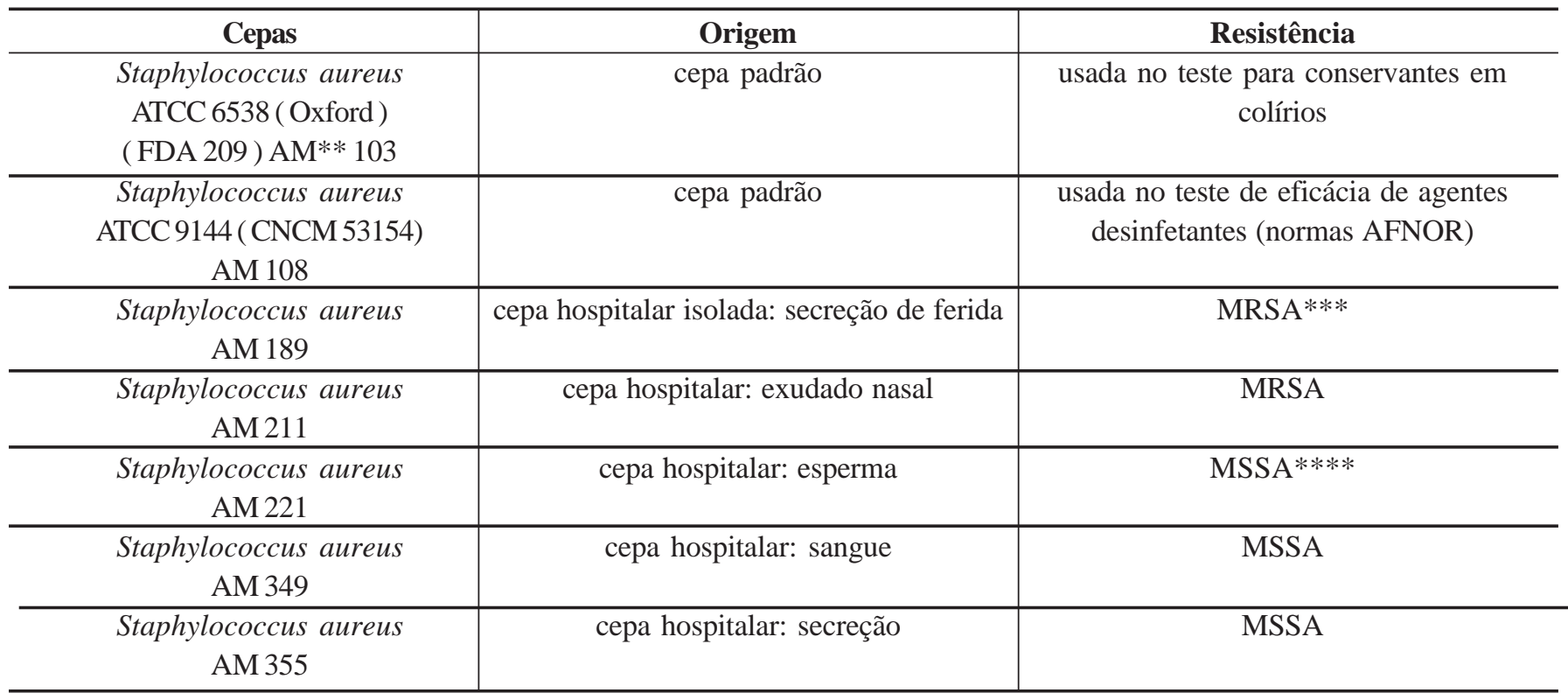

* Número total de cepas de Staphylococcus aureus testadas : 07

** AM: Coleção de culturas microbianas do Laboratório de Análises Microbiológica, Departamento Ciências Farmacêutica, UFPE

*** MRSA, S. aureus meticilina resistente

**** MSSA, S. aureus meticilina sensível

Tabela 2. Plantas testadas

\begin{tabular}{l|l|l|l}
\hline Nome científico & Nome Popular & PU & IP \\
\hline Orbignya martiana & babaçu & pó de mesocarpo & inflamação em geral e feridas crônicas \\
\hline Argemone mexicana & cardo Santo & folhas/flores & antinflamatório \\
\hline Ageratum conyzoides & mentrasto & folhas/flores & analgésico, antinflamatório \\
\hline Equisetum yeamalis & cavalinha & folhas/flores & afecções do aparelho urinário \\
\hline Alternanthera brasiliana & terramicina & folhas & antinflamatório \\
\hline
\end{tabular}

PU - parte usada

IP - indicação popular

\section{Resultados e Discussão}

Os resultados obtidos são apresentados na tabela 3, com os fenótipos dos isolados de Staphylococcus aureus frente a treze antibióticos e no Figura 1 no qual aparece comparativamente a ação do antibiótico cloridrato de tetraciclina e das plantas cardo santo, babaçu e terramicina.

Para o extrato de babaçu à concentração de $30 \mathrm{mg} / \mathrm{ml}$, houve ação sobre as sete cepas testada com halos de 14 - 18 mm. Para esta planta já tinha sido comprovada uma atividade antiinflamatória $^{11}$

No caso de cardo santo a concentração de $24,8 \mathrm{mg} / \mathrm{ml}$, houve ação só sobre a cepa padrão ATCC 6538, com halos médios de $18 \mathrm{~mm}$.

Quanto o extrato bruto de terramicina à concentração de $65 \mathrm{mg} / \mathrm{ml}$ apresentou halos de até $22 \mathrm{~mm}$ sobre quatro das cepas estudadas. Este extrato teve uma ação bastante semelhante ao controle, o cloridrato de tetraciclina (halos de inibição de até $34 \mathrm{~mm}$ ).

Ambos o extrato e o controle agiram sobre seis das cepas em estudo, inclusive o Staphylococcus aureus (MRSA)AM.211, não apresentando atividade sobre a cepa Staphylococcus aureus AM 349, tetraciclina resistente (Figura 1).

O resultados encontrados não coincidiram com os obtidos por Bezerra ${ }^{4}$ bem que ele assinala uma atividade sobre Escherichia coli para a fração 15 (betacianínica) do extrato metanólico.

Visivelmente a presença de terpenóides e do pigmento betacianina na sua composição química podem ser responsáveis de uma atividade ${ }^{3}$.

Finalmente não detectamos uma atividade antimicrobiana para o extrato de mentrasto, diferentemente aos resultados apresentados por Samy ${ }^{14}$, sobre Streptococcus pyogenes. Uma explicação possível seria quanto à menor resistência do Streptococcus, um dos poucos germes ainda sensíveis à penicilina, em relação ao multirresistente Staphylococcus aureus. 
Tabela 3. Fenótipo dos isolados dos Staphylococcus aureus

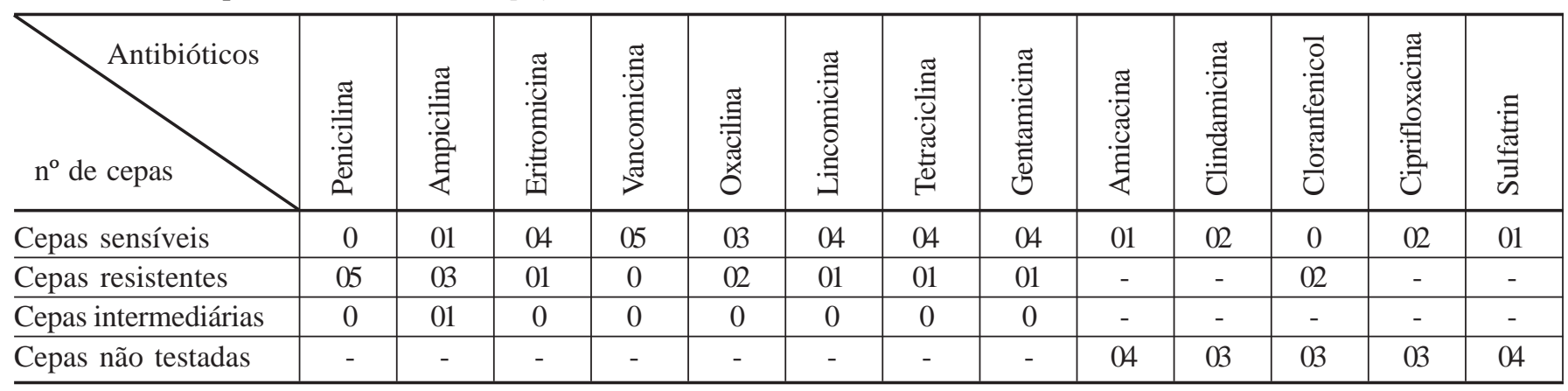

* Numero total de cepas isoladas usadas no teste: 05

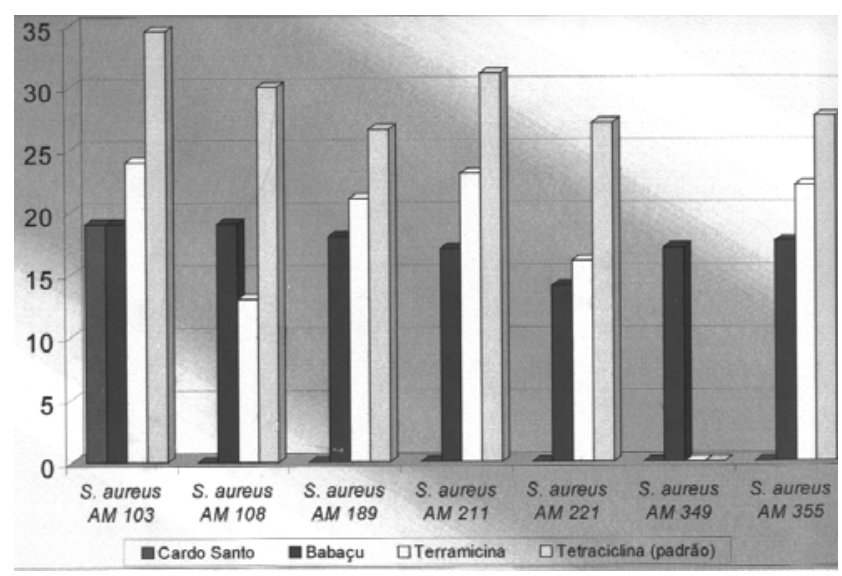

Figura 1. Staphylococcus aureus - halos de inibição (mm) das plantas medicinais e tetraciclina ( padrão)

\section{Conclusões}

Das cinco plantas em estudo, apresentaram atividade antimicrobiana o extrato de babaçu (Orbigiaya martiana), o extrato bruto de cardo santo (Argemone mexicana) e o extrato bruto de terramicina (Alternanthera brasiliana).

Por contra, não foi detectadas atividade sobre as cepas de Staphyloccoccus aureus para o extrato bruto de mentrasto (Ageratum conyzoides), que tinha ação assinalada sobre Streptococcus pyogenes.

A atividade apresentada pelo extrato terramicina, foi considerada interessante, porque vem justificar seu uso popular, assim com o fato de ter evidenciado uma atividade semelhante ao cloridrato de tetraciclina, inclusive sobre as cepas Staphylococcus aureus MRSA .

Na metodologia, a técnica de poço, difusão em ágar, que permite a difusão radial das substâncias e o tempo de predifusão à temperatura ambiente favoreceram a expressão da ação antimicrobiana.

Finalmente frente ao grave problema que representa a multirresistência do Staphylococcus aureus, interessa estudar tratamentos alternativos aos antibióticos tradicionais, tais como são os produtos naturais, ou mesmo antisépticos, cuja reintrodução vem sendo pleiteada pelos anglo-saxões.

\section{Referências}

${ }^{1}$ Akelere, O. Importance of Medicinal Plants: WHO'S Programme in Natural Resources and Human Heallth. Elsevier AmsterdamLondon - New York -Tokyo, 1992

${ }^{2}$ Akerele, O; Programa OMS de Medicina Tradicional; Progresos y Perspectivas. Crónica de la OMS, 38 (2) : 83 -88, 1984

${ }^{3}$ Barboza, N.C.; Macedo, A. F.; Sato, A.; Esquibel, M.A. Efeitos de diferentes comprimentos de onda e hormônios sobre a morfogênese e produção de pigmentos em plântulas de Alternanthera brasiliana Kuntze, cultivadas "in vitro". XV Simpósio de Plantas Medicinais do Brasil . Águas de Lindóia, 02.036 pag. 110, outubro 1998

${ }^{4}$ Bezerra, J.D. Estudo Fitoquímico e Avaliação Farmacológica do extrato Bruto da Alternanthera brasiliana (L) Kunze . Tese Mestrado Universidade Federal de Pernambuco (UFPE), Recife - Pernambuco - Brasil, 2001

${ }^{5}$ Braga, R. Plantas do Nordeste: Especialmente do Ceará, $4^{\mathrm{a}}$ edição, Fortaleza, Editora Universitária UFRN, 1960

${ }^{6}$ Cruz, M.E.S.; Batista, M.A.; Inoue, M.H.;Fagan, C.; Tagami, O.K. Influencia de fatores climáticos no teor de óleo essencial de plantas medicinais. XV Simpósio de Plantas Medicinais do Brasil. Águas de Lindóia , 02.053 pag. 114, outubro 1998

${ }^{7}$ Farnsworth, N.R.; Akerele, O; Bingel, A.S.; Soerjato, D.D.; Zhengang, G. Medicinal plants in therapy . Bulletin of the Wold Health Organization 63 (6): 965 -981 (1985)

${ }^{8}$ Freitas, E.L.S.; Moura, A.C.A; Fontes, S.G.F.; Maia, M.B.S. Estudo do efeito de Orbignia phalerata Mart.( babaçu) sobre as lesões gástricas induzidas por etanol ou indometacina. XV Simpósio de Plantas Medicinais do Brasil . Águas de Lindóia, 01.210 pag. 94, outubro 1998

${ }^{9}$ Gijndidza, M. Antimicrobial activity of helinus Integrifolius. Fitoterapia. 53 (3) : 181 - 183, 1987

${ }^{10}$ Lopes M.F.G.; Nogueira, C.M.D.; Almeida, M.M.B.; Vasconcelos, N.M.S.; Morais, M.N.T.; Souza, R.M.S. Plantas Medicinais; uma abordagem analítica. XV Simpósio de Plantas Medicinais do Brasil . Águas de Lindóia , 03.130 pag. 148, outubro 1998

${ }^{11}$ Maia, M. B. Estudo de Atividade Antinflamatória e Outros Efeitos Farmacológicos Relacionados a Orbignia phalerata Mar.Tese Mestrado, Universidade Federal do Ceará ( UFC)Ceará - Fortalesa - Brasil, 1987 
${ }^{12}$ Matos, F. J. A. Farmácias Vivas, Fortaleza, 1989

${ }^{13}$ Moraes, A.P.; Silva, J.V.; Machado, M.I.L.; Matos, F.J.A.; Fonteles, M.C.; Gomes, J.A.M.; Pessoa, C. E. Morais, M.O. Avaliação da atividade de plantas do nordeste brasileiro em tumores experimentais. XI Simpósio de Plantas Medicinais do Brasil. João Pessoa, pag 4.45, setembro 1990

${ }^{14}$ Samy, R.P.; Ignacimuthu, S; Raja, D.P. Preliminary screening of ethnomedicinal plants from India Journal of Ethnopharmacology 66: 235-240, 1999 